Article

\title{
Integrating Global Open Geo-Information for Major Disaster Assessment: A Case Study of the Myanmar Flood
}

\author{
Suju Li ${ }^{1}$, Yan Cui ${ }^{1, *}$, Ming Liu ${ }^{1}$, Haixia He ${ }^{1}$ and Shirish Ravan ${ }^{2}$ \\ 1 National Disaster Reduction Center of China, No. 6 Guangbaidong Road, Chaoyang District, Beijing 100124, \\ China; lisuju@ndrcc.gov.cn (S.L.); liuming@ndrcc.gov.cn (M.L.); hehaixia@ndrcc.gov.cn (H.H.) \\ 2 United Nations Office for Outer Space Affairs, United Nations Office at Vienna, \\ Vienna International Centre, Wagramerstrasse 5, A-1220 Vienna, Austria; shirish.ravan@unoosa.org \\ * Correspondence: cuiyan@ndrcc.gov.cn; Tel.: +86-10-5281-1176
}

Received: 5 May 2017; Accepted: 29 June 2017; Published: 6 July 2017

\begin{abstract}
Major disasters typically impact large areas, cause considerable damages, and result in significant human and economic losses. The timely and accurate estimation of impacts and damages is essential to better understand disaster conditions and to support emergency response operations. Geo-information drawn from various sources at multi spatial-temporal scales can be used for disaster assessments through a synthesis of hazard, exposure, and post disaster information based on pertinent approaches. Along with the increased availability of open sourced data and cooperation initiatives, more global scale geo-information, including global land cover datasets, has been produced and can be integrated with other information for disaster dynamic damage assessment (e.g., impact estimation immediately after a disaster occurs, physical damage assessment during the emergency response stage, and comprehensive assessment following an emergency response). Residential areas and arable lands affected by the flood disaster occurring from July to August 2015 in Myanmar were assessed based on satellite images, GlobeLand30 data, and other global open sourced information as a study case. The results show that integrating global open geo-information could serve as a practical and efficient means of assessing damage resulting from major disasters worldwide, especially at the early emergency response stage.
\end{abstract}

Keywords: major disasters; damage assessment; global open; geo-information; GlobeLand30

\section{Introduction}

Major disasters pose global challenges [1] around the world not only because they typically affect large areas and can have impacts that cross national borders, but also because they typically incur considerable damages to residents, societies, and economic systems. Some disasters even require international assistance for the emergency response and relief. Annually, roughly 300 major disasters are recorded under the Centre for Research on the Epidemiology of Disasters (CRED) through its Emergency Events Database (EM-DAT) [2]. Timely and accurate assessments of damage are critical to better understand the overall impacts of disasters and to support more scientific decision making that can guide emergency rescue, relief, and reconstruction efforts. Global open geo-information and other information drawn from multiple sources, including formats of different levels and scales based on appropriate integration approaches, could not only be used to estimate the extent of damage involved, but also to observe spatial and temporal patterns for disaster damage assessments that support disaster management in instructive and effective ways [3].

Disaster assessments involve the use of dynamic processes determined based on different emergency stages, accessible data sources, and outcome accuracies, and can be divided into three 
types: rapid impact estimations, physical damage assessments, and comprehensive assessments. As more time passes after a disaster occurs, more sourced and detailed data can be accessed for damage assessments, thus rendering the results more accurate. Rapid impact estimations are typically conducted within hours to days following a disaster and are based on experimental approaches (e.g., the Prompt Assessment of Global Earthquake for Response (PAGER) system [4] developed by the U.S. Geological Survey and the Global Disaster Alert and Coordination System (GDACS)) [5] that can be used to initially determine the possible impacts for disaster managers. Comprehensive disaster assessments are conducted based on thorough and detailed datasets using multiple approaches, including ground surveys, when disaster conditions are stable and when emergency response operations are ending, which can sometimes occur after several months [6,7], in turn producing accurate and thorough outcomes for further recovery and reconstruction planning. Periods of time ranging from hours to weeks or months are required for disaster rescue and emergency relief efforts when physical damage assessments are required. Populations, buildings, infrastructure, and other physical assets are the main affected elements that are assessed after a disaster. As there is typically a lack of complete post disaster information due to time limitations, physical damage assessments are conducted by integrating as much available information as possible. Satellite remote sensing methods integrated with other geo-information tools are widely used for physical damage assessments. As disaster conditions are changing at this stage, damage assessment information requirements for supporting disaster response measures are also dynamic and urgent. As more data become available with the passage of time after a disaster occurs, the accuracy and covered area of a physical damage assessment also improves.

With the development of advanced geo-information technologies and with the promotion of global open data, enormous global open geo-datasets are now accessible and could be utilized for dynamic disaster assessments when integrated with other information. Although global open source datasets are typically available at a coarser scale relative to local scale geo-datasets, they are suitable for efficient and large-scale damage estimations as they are created in standard formats and are easily accessible. The existing global dataset with information on elements for disaster assessment includes hazard, exposure, post-disaster, and auxiliary data. The Global Land Cover (GLC) map is a widely used global open dataset that could be employed as a source of disaster exposure data. A number of medium resolution (300-1000 m) GLC maps have been developed over the last two decades [8]. With the development of open satellite archives and large data processing and storage tools, higher resolution (less than $30 \mathrm{~m}$ ) GLP maps such as Globeland30 [9,10] have been produced since 2013 [11]. Global settlement mapping products such as GUF and GHSL datasets have been created at an unprecedented spatial resolution of $12 \mathrm{~m}$ [12]. Such high-resolution GLC mapping products will greatly improve accuracy levels and timelines when used for disaster damage assessment, and especially when applied for countries lacking a uniform national exposure dataset. Such products will also dramatically facilitate international cooperation in emergency mapping for major disasters.

Global geo-information has been used for major disaster dynamic assessments in conjunction with other information for data accessing, information analysis, and product use, in consultation with corresponding policies, standards, platforms, and cooperation initiatives. In total, 75 countries have joined the Open Government Partnership [13] for open government data use for various purposes (e.g., for disaster emergencies with guidance from the Open Data Charter of 2015) [14]. Within the framework of the International Charter on "Space and Major Disasters", more than 40 operational earth observation satellites with a variety of optical or synthetic aperture radar (SAR) sensors can be mobilized and tasked to acquire earth observation data of a disaster affected area during the major disaster emergency stage [15]. Through its Common Infrastructure (GCI), GEOSS links existing and planned spatial information resources and provides access to existing databases and portals through the 'GEOSS Portal' for decision makers and emergency managers [16]. The European community (INSPIRE) also promotes open access to such data for disaster management purposes through structured and standardized data management initiatives. The European Copernicus Programme 
not only openly provides sentinel satellite images, but also emergency mapping services. The United Nations Space-based Information for Disaster Management and Emergency Response (UN-SPIDER) and Operational Satellite Applications (UNOSAT) Programmes, as well as other initiatives, have been developed to deliver spatial information services for disaster risk reduction and emergency responses.

Despite these efforts, gaps still exist between the information required and its availability, especially in regards to damage assessments. For instance, while it can take days to months to acquire post disaster information covering an entire affected area either through survey or earth observation approaches, disaster managers need this information in almost real time. Existing information is occasionally available from various agencies in different formats, and interoperability issues can result due to a lack of standardized formats, methodologies, and sharing mechanisms. The Sendai Framework for Disaster Risk Reduction: 2015-2030 [17] (adopted at the third UN world conference held in Sendai, Japan, on 18 March 2015) makes use of existing space and geo-information through open data promotion and international cooperation. Geo-information could be integrated at global and local levels to address gaps in information affecting disaster damage assessments, while expanding global open datasets. In this paper, available global open geo-information and the framework of dynamic disaster assessment approaches are reviewed and elaborated on. A major flood occurring in Myanmar from July to August 2015 is taken as a study case. Damages are dynamically estimated from global open geo-information, earth observation images, and other information. The paper also presents challenges and perspectives related to integrating multi-sourced geo-information for damage assessments in a consideration of past and current developments in this domain.

\section{Global Open Geo-Information and Integrated Framework}

\subsection{Available Global Open Dataset}

Disaster damage assessments are based on hazard, exposure, and disaster data of an appropriate scale and resolution. With the advent of web-based geo-information platforms and with the promotion of global open source data, an increasing number of global geo-datasets are now accessible for disaster management purposes. Although they are available at coarser scales relative to local geo-datasets, they are suitable for fast and large-scale damage estimations as they are offered in standard formats. Global datasets are typically derived from top down integration approaches. Some global open geo-datasets that could be used for damage assessments are described below.

The scope and intensity of a hazard event must be defined for the estimation of other affected elements. The spatial characteristics of a hazard event are typically defined by combining theoretical and empirical knowledge with sparsely discrete observational hazard-related data. Real time or near real time access to hazard event information is critical for decision makers when first alerted to disaster situations. ShakeMaps is a widely used global open earthquake hazard information product developed through the U.S. Geological Survey Earthquake Hazard Program in conjunction with regional seismic network operators, which could provide near-real-time maps of ground motion and shaking levels following significant earthquakes through their website [18]. Global real time flood intensity (the depth above the threshold) and inundation maps are generated through the Global Flood Monitoring System using satellite-based precipitation and hydrologic models [19]. Near real time flood intensity levels at the 1/8th degree and at a $1 \mathrm{~km}$ resolution can be accessed [20]. The Currently Active Tropical Cyclones system is a real-time tropical cyclone product of The Regional and Mesoscale Meteorology Branch (RAMMB) of the NOAA that records the locations and intensity levels of track histories and forecasts [21]. The natural hazard viewer developed by the NOAA can monitor archives and assimilate tsunami, earthquake, and volcano data in terms of geo-locations and intensity levels [22].

Exposure data are critical for damage assessments. Empirical studies show that exposure data considerably influence the accuracy of disaster damage assessment results [23]. Resident, building, and infrastructure data are the most commonly used exposure elements for damage estimations. At the global scale, exposure data are typically based on national open statistical and census data, global 
databases, and remote sensing data. Complete and detailed geospatially linked exposure inventories are ideal information for efficiency damage estimations for all countries, but are rarely created and are not publicly available in most developing countries due to technical and policy-related limitations. Global open exposure dataset development is essential for global and national disaster damage assessments, for which a fine spatial resolution and up-to-date data are key features. The Gridded Population of the World, Version 4 (GPWv4) Population Density consists of estimates of human population density based on data consistent with national censuses and population registers for $2000,2005,2010,2015$, and 2020. Population count grids are derived by dividing population count grids by land area grids, and pixel values represent the number of persons per square kilometer [24]. Several global datasets derived from remote sensing imagery that describe spatial patterns of human settlement, artificial land, and built-up areas are important exposure data used for rapid post disaster impact estimations. The Global Urban Footprint was developed by the German Aerospace Center (DLR) based on the global datasets of the TerraSAR-X and TanDEM-X mission for between 2011 and 2013 at a 12-meter resolution [25] and has been available to scientists since the end of 2014 . The GlobaLand30 dataset is a global open dataset extracted from more than 20,000 Landsat and HJ-1 images at a 30-m resolution for 2000 to 2010. Artificial surfaces and cultivated land types can be used for disaster impact estimations [26].

Disaster information is used to evaluate disaster conditions and to further determine physical damage and the severity of damages incurred via administrative reporting, remote sensing, ground surveying, and crowdsourcing. The international disaster database (EM-DAT) is a widely used statistic ground-based disaster dataset that includes essential data on over 18,000 mass disasters occurring around the world from 1900 to the present. The database is updated weekly on its website [27]. Relief Web is a specialized digital service of the United Nations Office for the Coordination of Humanitarian Affairs (OCHA) through which crisis and disaster information is collected, updated, and analyzed around the clock from more than 4000 global information sources. It is offered on the web in the form of reports, maps, and data on conditions and assessments [28]. Since the turn of the century, earth observation technologies have increasingly been used to map impacts and to support emergency responses around the globe. As only a few countries own remote sensing satellites, the International Working Group on Satellite-based Emergency Mapping (IWG-SEM) [29] has successfully provided mapping services for major disaster emergency responses (e.g., International Charter Space and Major Disasters, European COPERNICUS Emergency Management Service, UN-SPIDER, UNOSAT, and Sentinel Asia) [30]. Post-disaster data provided through the above SEM mechanisms are offered in the form of damaged delineation and degree maps derived from satellite imagery. Crowdsourced mapping tools are innovative and rapidly developing technologies generated by volunteers worldwide who are working together to create free maps through online mapping platforms. The tools have been widely used for global emergency support as they are updated in real time. Of the increasing number of crowdsourcing platforms that are becoming available, OpenStreetMap (OSM) is the most widely used, offering a free, accurate, detailed, and up-to-date digital global map platform [31] collected through mobile tracing and satellite imagery interpretation. OSM has become a baseline dataset used to deliver major emergency mapping support for international humanitarian organizations. The Humanitarian OpenStreetMap Team (HOT) launched in January 2009 coordinates the creation, production, and distribution of free mapping resources in support of humanitarian relief efforts in many places around the world through OpenStreetMap. It proved successful when applied to the 2010 Haiti Earthquake [32] and 2011 Great Japan Earthquake [33]. Ushahidi, MapAction, GDACS live map, and UNOSAT live map are other crowdsourced mapping platforms that provide post-disaster and disaster map information at close to real time.

\subsection{Integrated Framework}

Disasters are complex, uncertain, and dynamic. The estimation of damages caused by disasters is also complex and nonlinear. As tools of integration, geo-information technologies could be used 
as a prerequisite for efficient damage estimations. The geo-information integration framework for disaster assessment is outlined in Figure 1. In fact, global and local geo-information integration is most effectively applied for major disaster damage assessment not only due to the amount of heterogeneous multi-sourced information required, but also due to various damage assessment requirements and the diverse methodologies and models that are available. When used for disaster damage assessment, explicit requirements should be a driving factor and are best handled for geo-information integration and not by integrating all forms of geographic analysis into one package, but by providing appropriate linkages to allow resource components to act in combination. Global and local geo-information integration has proven to be effective for efficient disaster damage assessment [34-38]. Such integration could be applied at the data, methodology, and information levels. For each level, both technical and non-technical approaches should be considered to support better estimations. A number of best application practices and modalities have been developed and should be used further.

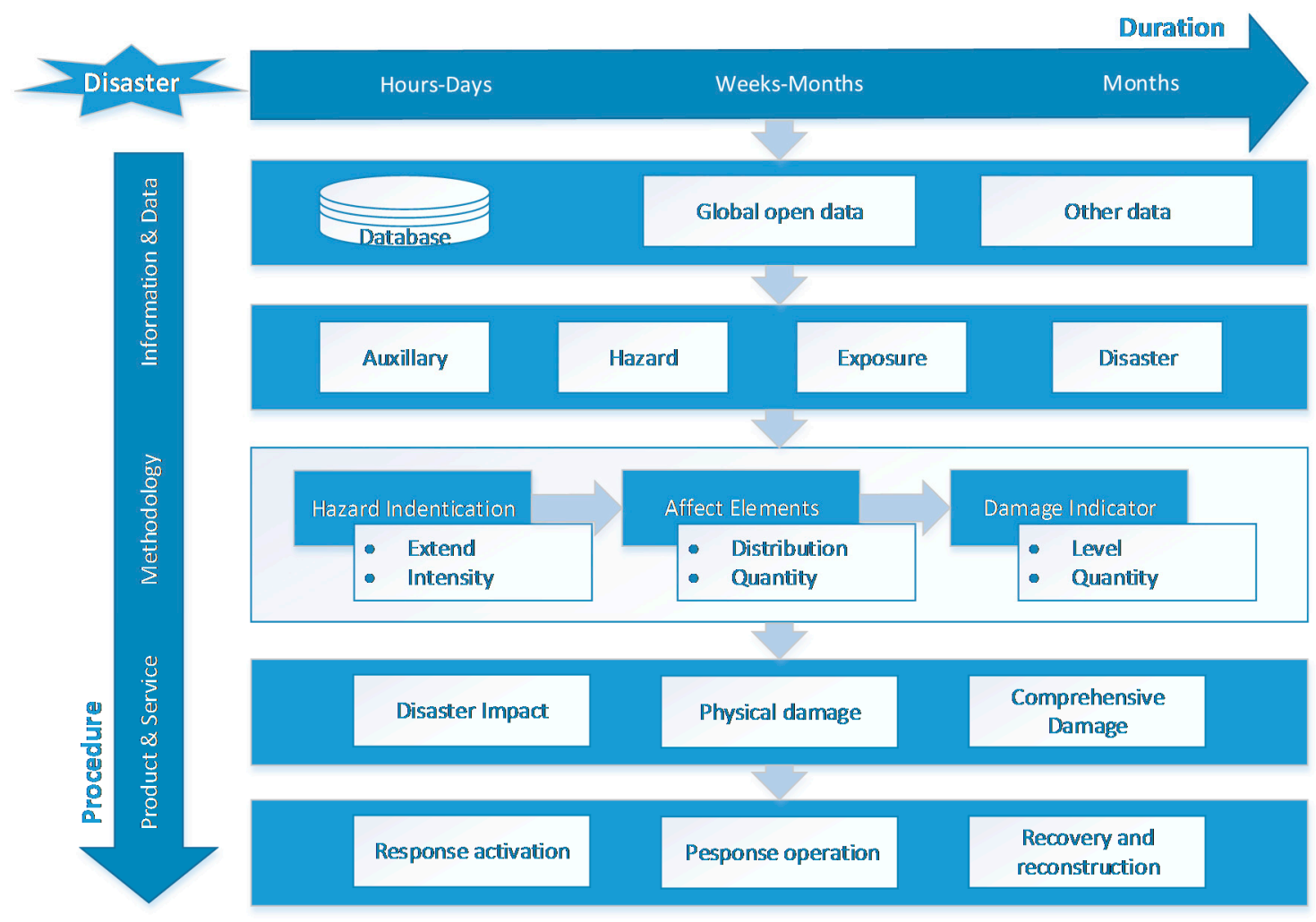

Figure 1. Geo-information Integration Framework for Disaster Assessment.

\subsubsection{Data and Information Integration}

The data are integrated for accessing and processing. Once a disaster occurs, various data on hazards, exposure levels, and disasters drawn from multiple sources must be collected within a limited amount of time for the damage estimation. Open source sharing mechanisms; local databases and new acquisition approaches such as remote sensing, crowdsourcing, surveying, and reporting, are commonly used means of data collection. Even single forms of data (e.g., post disaster remote sensing data) are typically drawn from more than ten remote sensing satellites operated by several agencies. Unlike global open data that are typically accessed through related websites, local (national) data are typically managed by several institutions. To facilitate access to a variety of information, data catalogs, information portals, dataset service platforms, and national spatial infrastructures serve as technical tools used for data collection integration. Beyond technical tools, open data policies, institutional collaboration on data sharing, and strategies for national spatial infrastructure promotion are non-technical integration approaches that can be used to improve data collection efficiency levels. 
Datasets, particularly local ones, are typically developed by different organizations through their own strategies designed for a particular target group (e.g., basic geographic information developed by survey agencies, remote sensing information produced by space agencies, and the ground disaster information collated by disaster management agencies). The diversity of strategies used leads to many inconsistencies and heterogeneities among datasets, hindering the collaborative utilization of such datasets. Such inconsistencies not only create technical issues related to formats, accuracy levels, currencies, data, and access networks, but also create non-technical issues (e.g., licensing arrangements). Well-defined geo-information data standards, metadata, and policies for sharing and use have generally been recognized as basic means of data integration. Some web-based geo-information integration tools have been developed for specific application services to identify data inconsistencies and for automatic integration. For example, the Open Transport Net project realized the integration of multi sourced open and geospatial datasets in the transportation domain, for which both standards and tools were facilitated as the approaches of data interoperability [38]. For some major disasters, geo-databases have been shared through web services for specific groups to facilitate crowd participation for damage assessments.

\subsubsection{Methodology Integration}

Disaster assessments are the integrated products of component information on the extent and intensity of hazards, on the distribution and number of affected elements, and on the quantity and quality of damages incurred. For each component listed above, various methodologies and models can be used for analysis and extraction. For rapid damage estimations, affected populations, cities, and buildings are typically roughly assessed based on experimental methodologies by integrating the earthquake intensity, exposure population density, and population vulnerability data. For instance, affected population estimated methodologies developed by PAGER integrate the global scale ShakeMap, Landscan populations [39], and national level population vulnerability data for past earthquakes. After predictive damage assessments are conducted, the degree of damage to each element is typically derived from local post-disaster information for the validation of final outcomes. Degrees of damage are typically defined by integrating affected elements with damage level information by sampling post-quantitative damage information for certain points or small-scale areas through high resolution remote sensing, crowdsourcing information, or field surveys, and by then deducing the damages incurred to an entire area by extrapolation or interpolation. For this type of damage assessment, plenty of models and methodologies have been developed for almost all damage indicators. For comprehensive damage assessments, all information needed is available for integrated utilization. For some major disasters, all damaged physical elements have been surveyed through various means of damage assessment. Damage information derived from different approaches is synthesized and verified to guarantee the accuracy of the final results [40-42].

Every methodology and model has unique application conditions, advantages, and limitations in terms of information availability levels, professional capabilities, and user requirements. Portals for categorizing related methodologies through guidelines, handbooks, or specifications are very helpful for integrated use and could define integrated approaches according to phases, scales, proceedings, or elements. The MapAction and Satellite Emergency Mapping guidelines are two of the best practices in this regard. The transfer of universal applicable methodologies into software tools through standardized programming and an explicit handbook for open use will dramatically assist countries with less geo-information available for professional purposes. At the same time, utilization feedback for different areas or conditions could facilitate the modification and refinement of methodologies. National cooperation and initiatives, global open promotion, and licensing are non-technical issues of integration promotion. 


\subsubsection{Product and Service Integration}

Geo-information platforms have been recognized as efficient tools for geo-information integration based on disparate information resources and dynamically produced disaster assessment products of different formats for multiple disaster management stakeholders. Furthermore, users from disaster management communities typically have no geo-professional background. Geo-information platforms based on GIS technologies can integrate diverse resources and should be loosely coupled for tailored recombined use. For countries that lack professional capabilities, the information serving function of the platform can be addressed through the USGS Hazard viewer, GDACS, and the PDC information platform. For countries with strong professional capacities, flexible platform function compound capacities are important (e.g., the GEO GRID Platform for Integrated Earth Sensing and the Digital Service File). Some disaster management systems such as the GAR for Tangible Earth [43] and the immersive environment OpenSim training tools [44] have been developed based on new technologies of the virtual environment and mobile internet, which provide the public with impressive experience disaster information and training.

\section{Study Area, Data and Workflow}

\subsection{Study Area}

Myanmar lies between latitudes $9^{\circ}$ and $29^{\circ} \mathrm{N}$ and longitudes $92^{\circ}$ and $102^{\circ} \mathrm{E}$, and covers a total area of 678,500 square kilometers. Myanmar is bordered by India and Bangladesh to the west, by Thailand and Laos to the east, and by China to the north and northeast. To the south, roughly one third of Myanmar's perimeter of $5876 \mathrm{~km}$ (3651 miles) forms an uninterrupted coastline of $1930 \mathrm{~km}$ (1200 miles) along the Bay of Bengal and the Andaman Sea. Much of the country lies between the Tropic of Cancer and the Equator. The country lies in Asia's monsoon region with its coastal regions receiving over $5000 \mathrm{~mm}$ of rain annually. Annual rainfall in the delta region reaches approximately $2500 \mathrm{~mm}$, while levels reach less than $1000 \mathrm{~mm}$ in the Dry Zone of central Myanmar. As of February 2011, Myanmar consisted of 14 states and regions and of 330 townships. According to the country's 2014 census, Myanmar has a population of 51 million. Myanmar is an agricultural country with its main agricultural product being rice, accounting for roughly $60 \%$ of the country's cultivated land area [45]. The country's cultivated land is mainly distributed across the country's central and southern regions as showed in Figure 2.

Myanmar is vulnerable to a broad range of natural disasters. Its coastal regions are particularly exposed to cyclones, tropical storms, and tsunamis, while at the same time, rainfall induced flooding recurs almost annually across the country. In addition, the whole country is at risk of earthquakes, droughts, and fires, while the country's mountainous regions are also exposed to landslide risks. Myanmar is currently ranked 10th out of 191 countries on the Index for Risk Management (INFORM), which assesses the risks of humanitarian crises and disasters that could overwhelm a nation's capacity to respond [46]. Cyclone Nargis, which hit in May 2008, has been the most devastating natural disaster to occur in the country's history, resulting in 138,000 deaths. According to CRED statistics, 30 natural disasters, including 15 floods, occurred in Myanmar and killed 139,000 people from 2000 to 2015. The Government Focal Point for Disaster Preparedness and Response Program managed by the Ministry of Social Welfare, Relief and Resettlement (MSWRR) is responsible for disaster risk management, emergency relief, and disaster information management.

From July to August 2015, Myanmar was hit by a major flood disaster with multiple landslides upon the onset of heavy monsoon rains in combination with the KOMEN typhoon occurring on 30 July 2015. According to MSWRR statistics, by the end of August 2015, the flood had affected 12 of Myanmar's 14 states and regions and 1.6 million people, of which at least 117 lost their lives. More than 390 ha of arable land and considerable infrastructure services were destroyed [47]. On 31 July of that year, the President of Myanmar declared the Chin and Rakhine states and Magway and Sagaing regions as flood disaster zones and welcomed international assistance. One national satellite 
emergency mapping and satellite operations agency, the National Disaster Reduction Center of China (NDRCC), is responsible for emergency mapping not only for natural disasters in China, but also for other countries. The NDRCC has provided mapping services in support of more than 20 major disaster emergencies occurring in other countries. At Myanmar's official request, the NDRCC coordinated four Chinese earth observation satellites and provided satellite imagery and mapping services integrated with global open datasets for the flood emergency response.

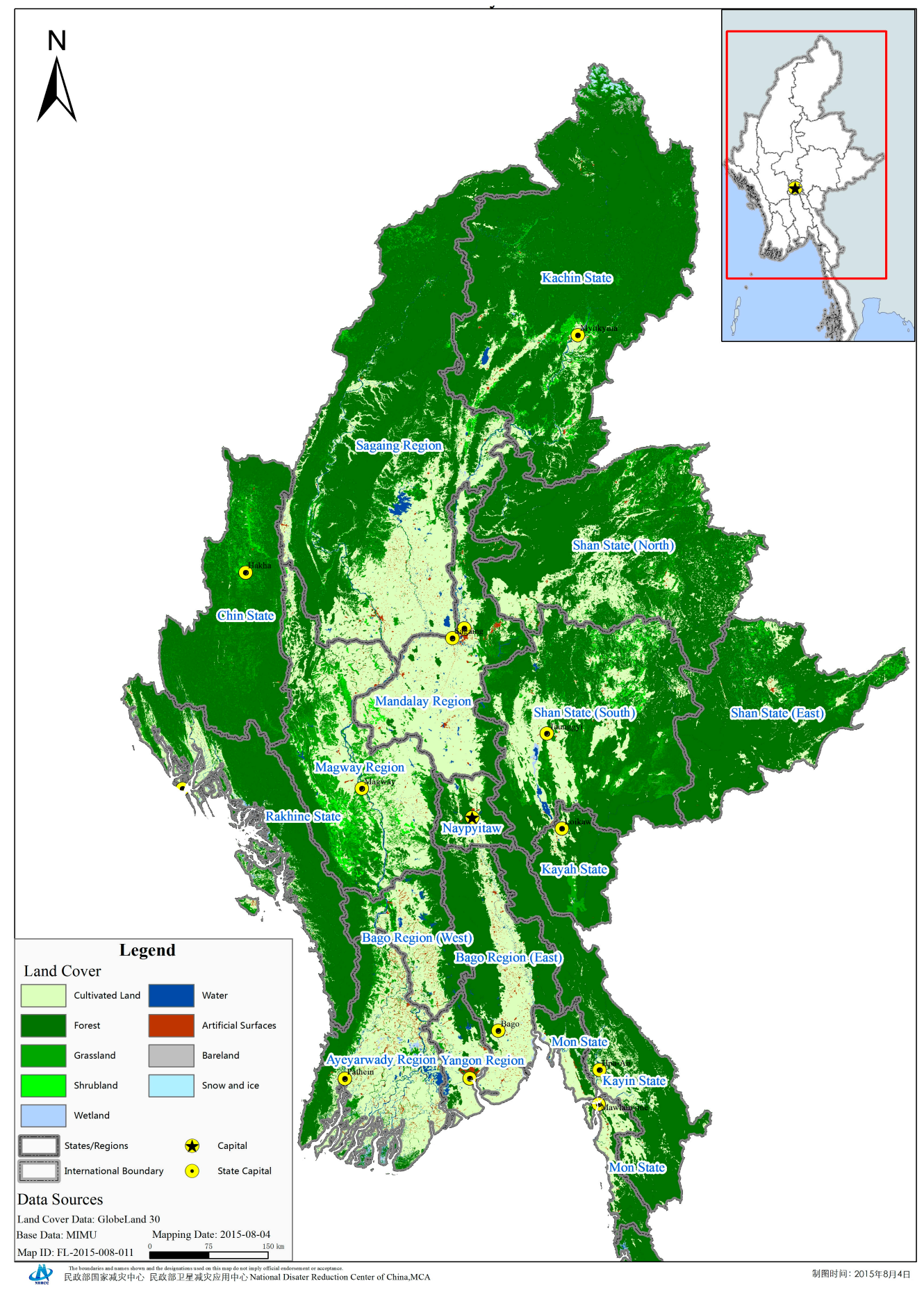

Figure 2. Landcover Map of Myanmar of 2010. 


\subsection{Data}

In carrying out its flood emergency mapping service for Myanmar, the NDRCC activated a data emergency acquisition mechanism to access as much available data as possible through different approaches. One approach involved collecting and processing satellite images from its database. Another approach used involved coordinating Chinese satellites for disaster observations. Exposure, auxiliary and post-disaster data were also accessed through a global open sourced approach. By 14 August 2015, 73 images from four satellites of the flooded area had been accessed, including 25 pre-disaster images drawn from HJ-A/B satellites covering the entire territory of Myanmar (Figure 3) and 48 post-disaster images drawn from $\mathrm{HJ}-\mathrm{A} / \mathrm{B} / \mathrm{C}$ and SJ-9A satellites covering the entire country with coverage shown in Figure 4. The dates and quantities of images used are outlined in Table 1. Satellite images were used for water body information extraction.

Table 1. Data Used for Flood Impact Estimations.

\begin{tabular}{|c|c|c|c|c|c|}
\hline Type & Name & Format and Source & Date & $\begin{array}{l}\text { Coverage, } \\
\text { Number and } \\
\text { Resolution }\end{array}$ & Application \\
\hline \multirow{6}{*}{$\begin{array}{l}\text { Global } \\
\text { Open } \\
\text { Datasets }\end{array}$} & GLC30 & $\begin{array}{l}\text { Raster; GLC30 platform, } \\
\text { http:/ / globallandcover.com }\end{array}$ & 2010 & Global, $30 \mathrm{~m}$ & $\begin{array}{l}\text { Affected arable } \\
\text { land estimation }\end{array}$ \\
\hline & Township & \multirow{4}{*}{$\begin{array}{c}\text { Vector; MIMU web, } \\
\text { http:/ / www.themimu.info/ }\end{array}$} & February 2012 & \multirow{4}{*}{ Whole country } & Affected residential \\
\hline & Village & & February 2012 & & area assessment \\
\hline & $\begin{array}{l}\text { Province } \\
\text { Border }\end{array}$ & & April 2014 & & $\begin{array}{c}\text { Affected province } \\
\text { estimation }\end{array}$ \\
\hline & $\begin{array}{l}\text { Country } \\
\text { Border }\end{array}$ & & April 2014 & & $\begin{array}{c}\text { Affected } \\
\text { administrative unit } \\
\text { estimation }\end{array}$ \\
\hline & $\begin{array}{c}\text { Post } \\
\text { Disaster } \\
\text { Information }\end{array}$ & $\begin{array}{l}\text { Reports; OCHA web, } \\
\text { http://reliefweb.int/ }\end{array}$ & August 2015 & Flooded area & $\begin{array}{l}\text { For reference and } \\
\text { validation }\end{array}$ \\
\hline \multirow{4}{*}{$\begin{array}{l}\text { Remote } \\
\text { Sensing } \\
\text { Images }\end{array}$} & $\begin{array}{l}\text { HJ-1A/B-CCD } \\
\text { Image }\end{array}$ & NDRCC & May 2015 & $\begin{array}{l}\text { Whole country, } \\
22 \text { frames, } 30 \mathrm{~m}\end{array}$ & $\begin{array}{l}\text { Pre-flood water } \\
\text { extent extraction }\end{array}$ \\
\hline & $\begin{array}{l}\text { HJ-1A/B-CCD } \\
\text { Image }\end{array}$ & NDRCC & July-August 2015 & $\begin{array}{l}\text { Whole country } \\
\text { 33frames, } 30 \mathrm{~m}\end{array}$ & $\begin{array}{l}\text { Post-flood water } \\
\text { extent extraction }\end{array}$ \\
\hline & $\begin{array}{l}\mathrm{HJ}-1 \mathrm{C} \\
\text { Image }\end{array}$ & NDRCC & July-August 2015 & $\begin{array}{l}\text { Part flooded } \\
\text { area, } 8 \text { frames, } \\
20 \mathrm{~m}\end{array}$ & $\begin{array}{l}\text { Post-flood water } \\
\text { extent extraction }\end{array}$ \\
\hline & $\begin{array}{l}\text { SJ-9A-CCD } \\
\text { Image }\end{array}$ & NDRCC & August 2015 & $\begin{array}{c}\text { Part flooded } \\
\text { area, } 3 \text { frames, } \\
10 \mathrm{~m}\end{array}$ & $\begin{array}{l}\text { Post-flood water } \\
\text { extent extraction }\end{array}$ \\
\hline
\end{tabular}

The HJ-1A/B/C and Small Satellite Constellation for Environment and Disaster Monitoring and Forecasting (SSCEDMF) manage two optical satellites and one radar satellite. The HJ-A/B satellites were launched in September 2008 and both were fitted with CCD cameras to observe the Earth over $700 \mathrm{~km}$ areas at a ground pixel resolution of $30 \mathrm{~m}$ and across four spectrum bands. HJ-1C was launched in November 2012 with an S-wave band synthetic aperture radar (SAR) and with two working band modes and scanning image swath widths of $40 \mathrm{~km}$ and $100 \mathrm{~km}$, respectively. The SJ-9A satellite was launched in October 2012 and was fitted with a multispectral scanner with a spatial resolution of panchromatic $2.5 \mathrm{~m} / 10 \mathrm{~m}$ multispectrum and a swath width of $40 \mathrm{~km}$.

GlobalLandCover30 data were also accessed from an information service platform as exposure information. Baseline geographic data including township points, village points, provincial borders, and national borders were accessed from the Myanmar Information Management Unit (MIMU) [48], a service of the UN Country Team and Humanitarian Country Team based in Myanmar and managed by the UN Resident and Humanitarian Coordinator. These data were used for affected administrative 
unit estimations and referencing. Disaster information was collected from relief web for estimation validation and condition referencing.

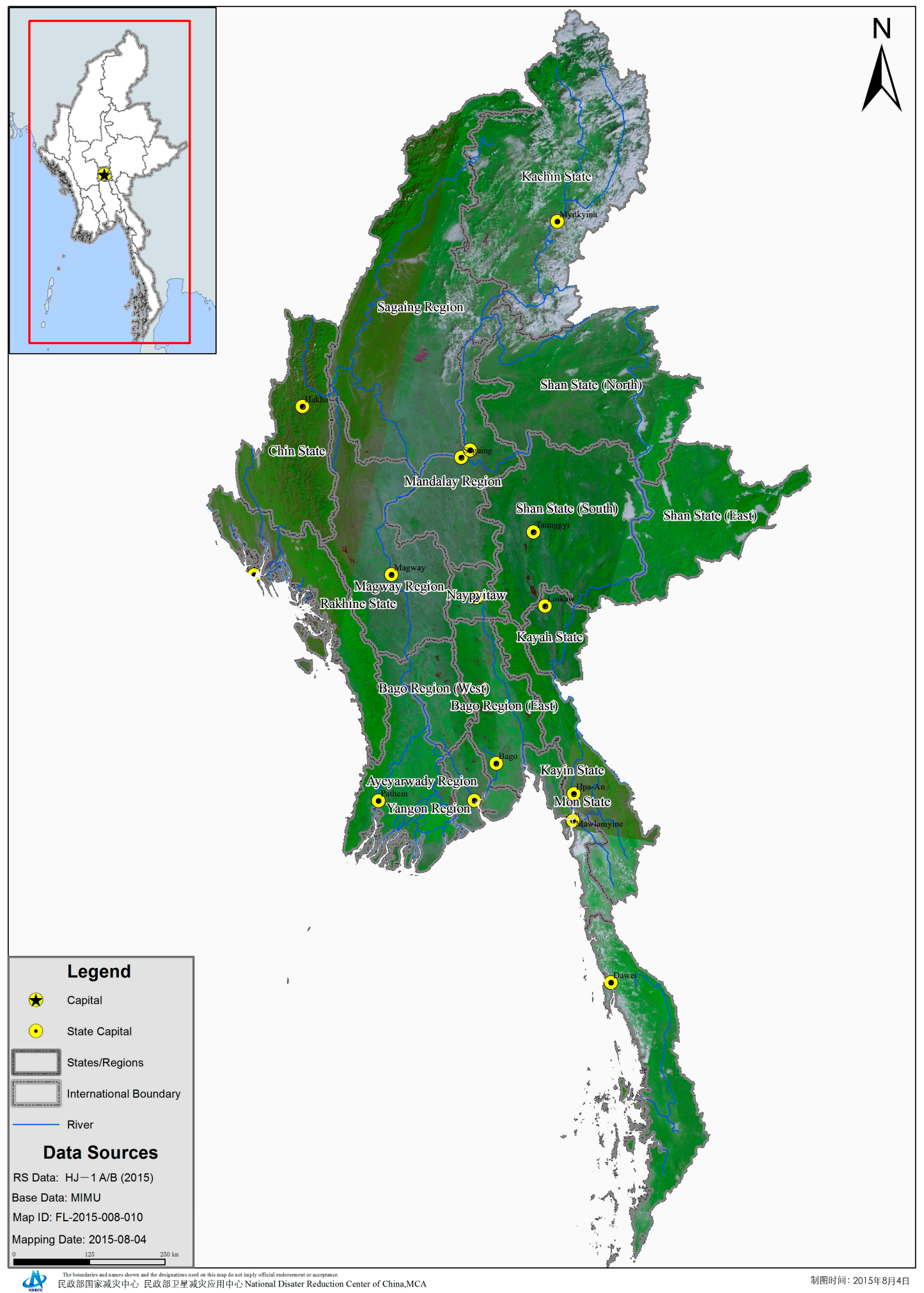

Figure 3. Pre-flood HJ-1A/B Images of Myanmar. 


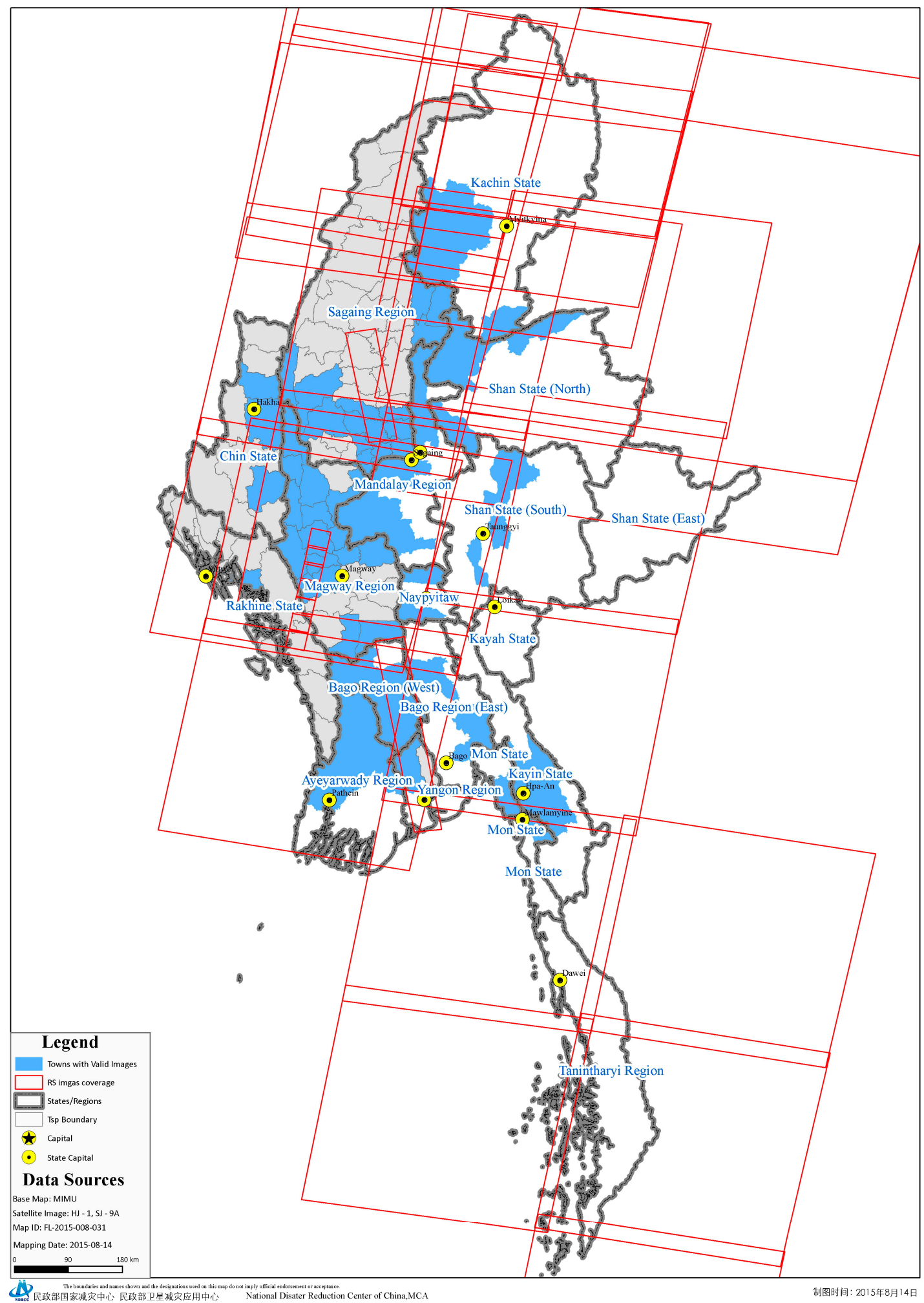

Figure 4. Post-Flood Satellite Image Coverage.

\subsection{Workflow}

Flood impacts were estimated from the acquired images over five phases as shown in Figure 5. First, all of the satellite images were subjected to radiometric and geometric correction pre-processing. Next, water body information was extracted via the region growing method [49] based on each scene 
of satellite images after pre-processing for pre- and post-disaster images. Third, all extracted pre-flood water body coverage polygons based on each image frame were geo-merged into one layer as pre-flood water body coverage data. All of the extracted post-flood water body coverage polygons were then geo-merged into one layer as post-flood coverage data. Fourth, the flood extent was determined through a comparative analysis and based on changes in pre- and post-flood water body coverage. Finally, GL30 and MIMU data were used as exposure elements to estimate the impacts of floods on administrative units, cropland, and human settlements using the flood extent information.

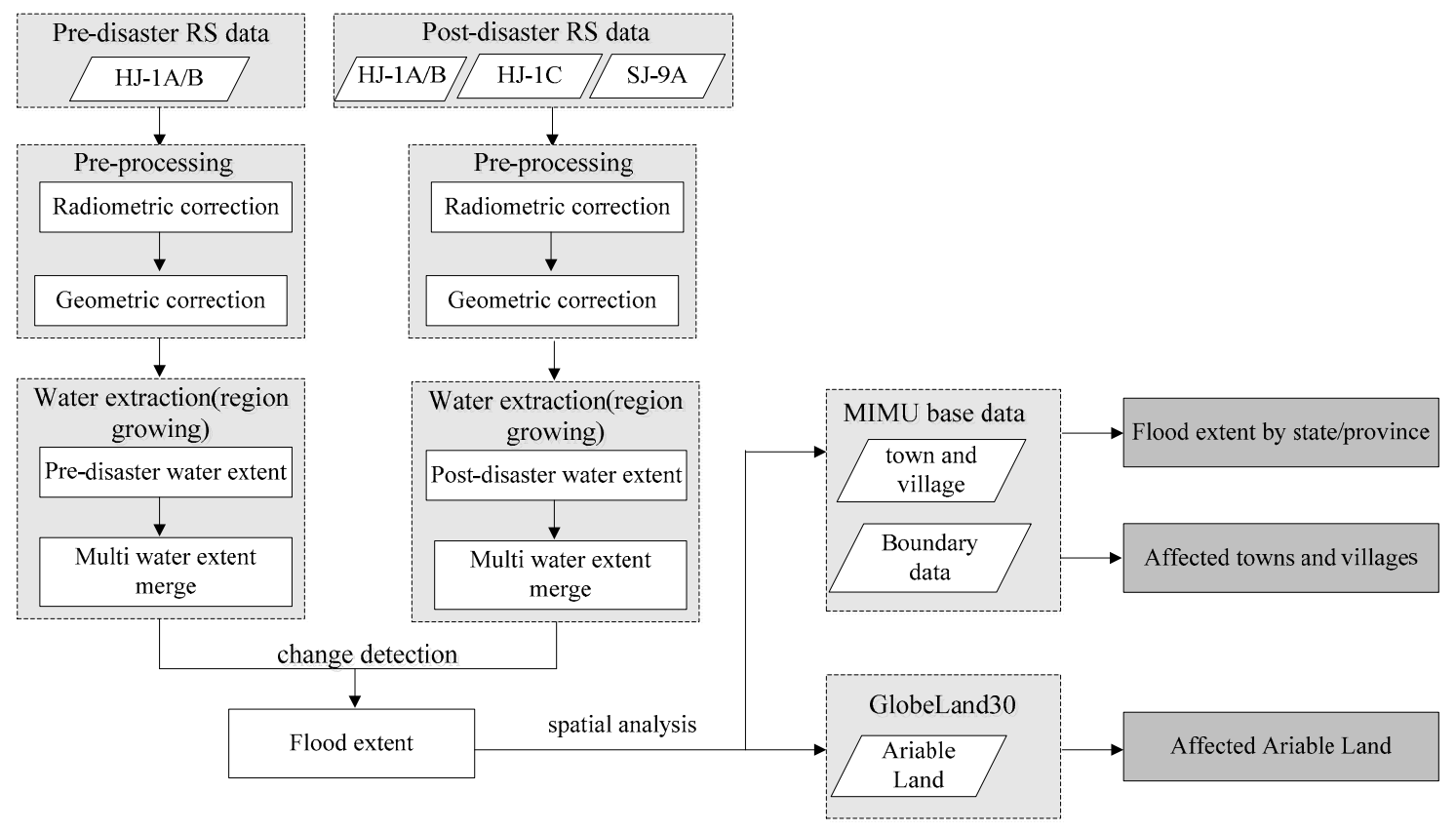

Figure 5. Flood Impact Estimation Workflow.

\section{Results}

\subsection{Flooded Extent}

According to the satellite remote sensing results, the highest flood extent for 4 to 14 August reached $123,349 \mathrm{~km}^{2}$ and affected 13 provinces and states as shown in Figure 6. Ayeyarwady, Bogo, Sagaing, and Magway were severely affected and the flood extent for each exceeded $1000 \mathrm{~km}^{2}$. Ayeyarwady was affected the most ( $3980 \mathrm{~km}^{2}$ flooded area). From the accumulated rainfall, the water levels of major rivers rose dramatically and spurred widespread basin flooding. Flooded areas were mainly distributed across valleys and plains along rivers. The northeastern Sagaing, southwestern Kachin, central and northern Ayeyarwady, and southwestern Bogo were flooded. The plains of central southern Sagaing, of central Magway, and of southern Rakhine were waterlogged. Chin was affected the least, presenting a flooded area of only $2.56 \mathrm{~km}^{2}$. 


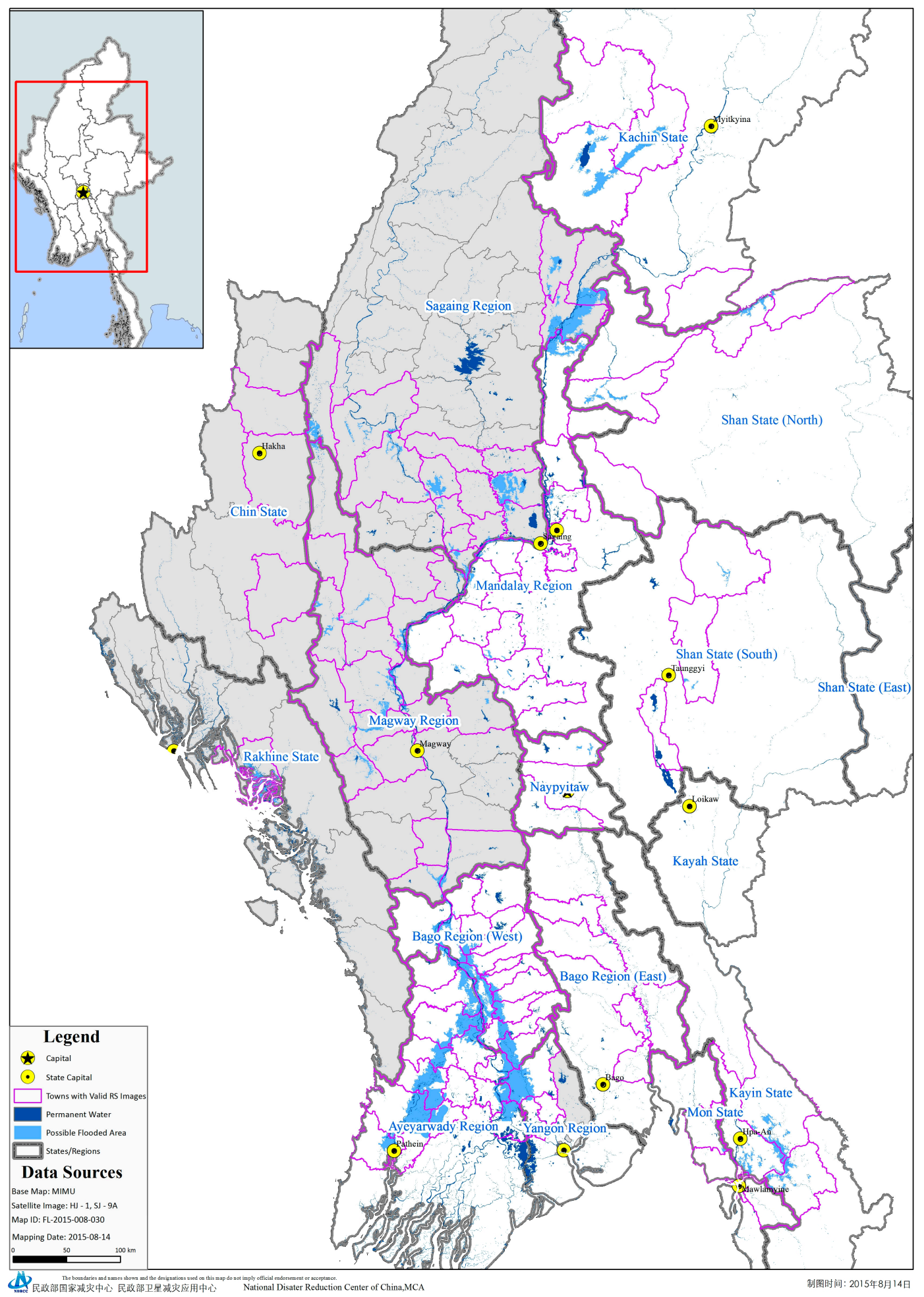

Figure 6. Flood Extents of the Myanmar Flood (as of 14 August).

\subsection{Impact Estimation}

Large farmland and residential areas were inundated along flooded rivers as shown in Figures 7 and 8 . In total, 1747 villages, 108 townships, and 909,700 ha arable land were flooded as a result of the flood disaster. Most flooded areas included arable land, accounting for $73.8 \%$ of the monitored flooded extent area. Regarding affected villages and towns and inundated arable land, Ayeyarwady, 
Bogo, and Sagaing were the most affected of the provinces and states. The state of Kachin included the largest proportion of flooded arable land, representing $78 \%$ of its flooded area. Rakhine, Naypyitaw, and Chin were only slightly impacted as shown in Table 2.

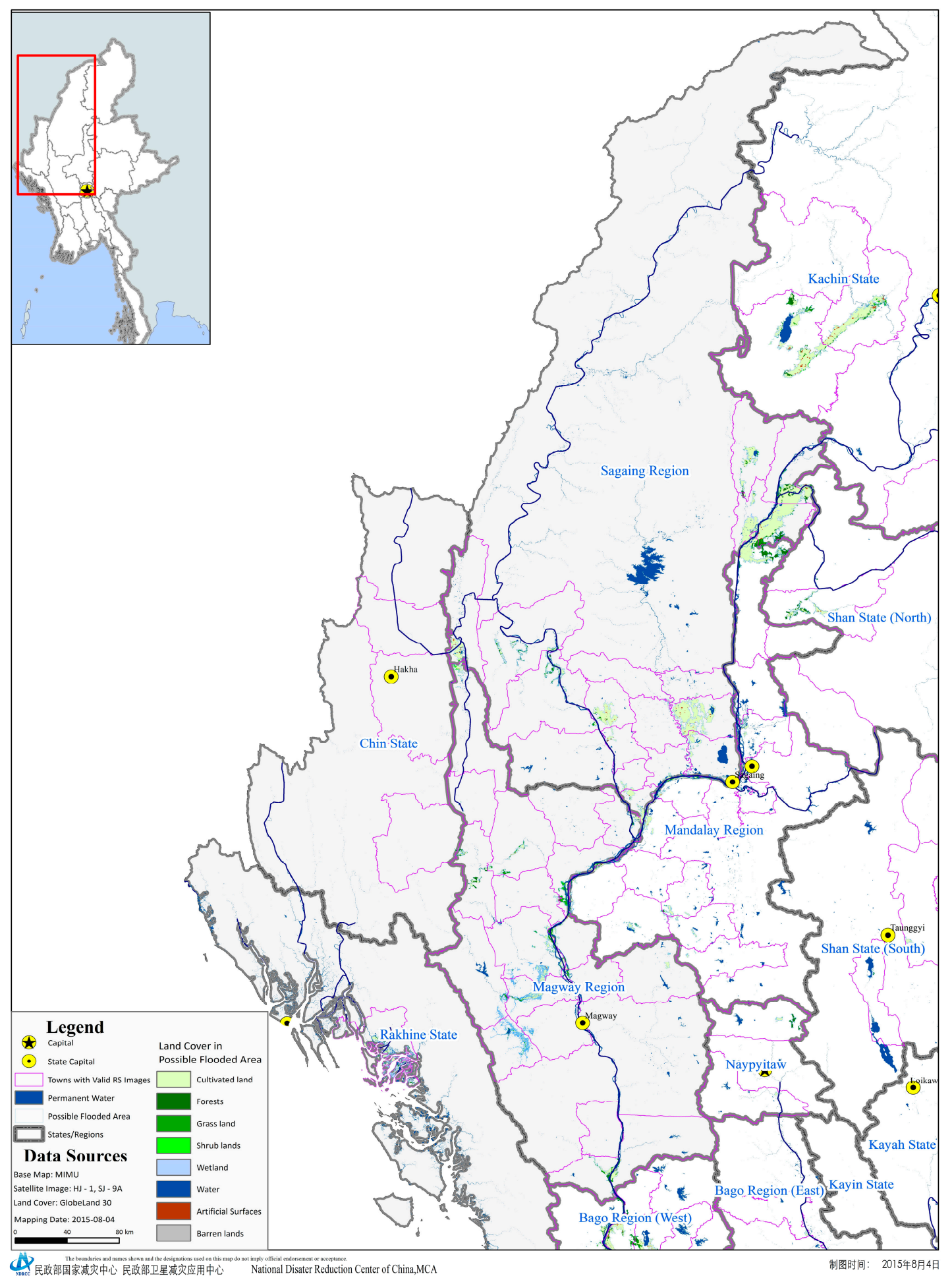

Figure 7. Land cover of the Flooded Areas. 
2015 Myanmar Flood Remote Sensing Mapping-Flooded Area in Rakhine,Bago,Ayeyarwady\&Magway on August 9th

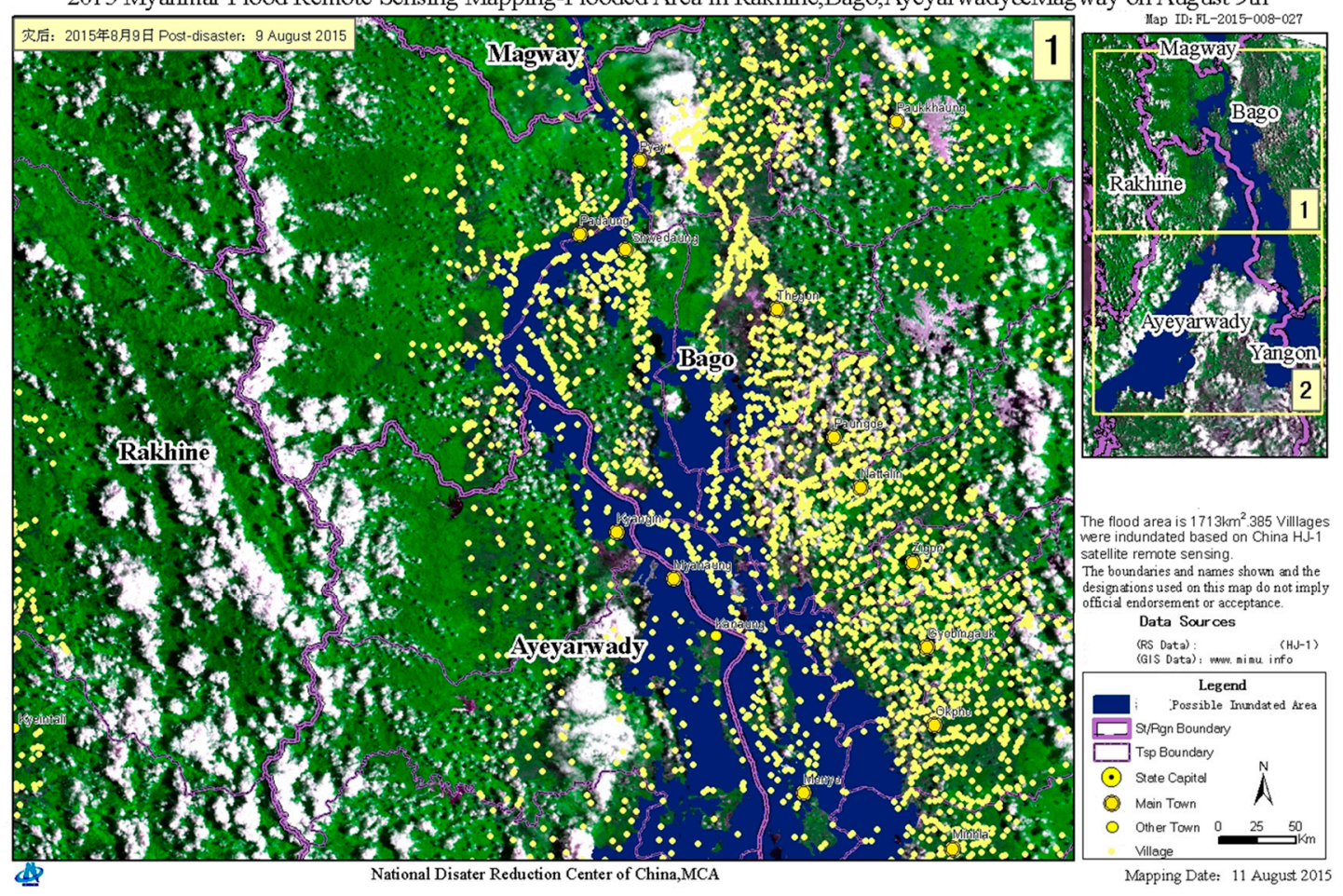

Figure 8. Flooded Residential Area Mapping Product.

Table 2. Flood Impacted Townships, Villages, and Arable Land.

\begin{tabular}{cccccc}
\hline Province/State & $\begin{array}{c}\text { Flooded } \\
\text { Extent } \mathbf{( k m )}\end{array}$ & $\begin{array}{c}\text { Affected Township } \\
\text { Number }\end{array}$ & $\begin{array}{c}\text { Affected Village } \\
\text { Number }\end{array}$ & $\begin{array}{c}\text { Flooded Arable } \\
\text { Land (1000 ha) }\end{array}$ & $\begin{array}{c}\text { Flooded Arable } \\
\text { Land Proportion (\%) }\end{array}$ \\
\hline Ayeyarwady & 3980.84 & 14 & 488 & 312.1 & 78.4 \\
Bago & 1861.44 & 18 & 485 & 129.7 & 69.7 \\
Chin & 2.56 & 3 & 0 & 8.0 & 31.3 \\
Kachin & 775.25 & 3 & 59 & 60.6 & 78.2 \\
Kayin & 679.93 & 3 & 79 & 48.3 & 55.2 \\
Magway & 1017.51 & 18 & 201 & 56.2 & 58.8 \\
Mandalay & 676.85 & 14 & 35 & 39.8 & 40.6 \\
Mon & 22.08 & 4 & 2 & 2.2 & 29.9 \\
Naypyitaw & 34.62 & 2 & 1 & 1.4 & 82.5 \\
Rakhine & 207.24 & 2 & 9 & 6.2 & 55.4 \\
Sagaing & 2124.31 & 16 & 304 & 175.2 & 82.9 \\
Shan & 325.16 & 8 & 38 & 18.0 & 73.8 \\
Yangon & 627.08 & 3 & 46 & 52.0 & 909.7 \\
Sum & $12,334.9$ & 108 & 1747 & & \\
\hline
\end{tabular}

\subsection{Validation and Application}

Due to a lack of ground measurement data, the assessed flooded extent and affected elements have not been quantitatively verified. Disaster information included in the OCHA report issued in mid-August was used for our qualitative validation analysis. For the estimated flooded extent, 13 provinces and states were affected, and satellite remote sensing results show that Naypyitaw was not included in the list of affected areas in the report and was estimated as only slightly affected. Ayeyarwady was estimated as the most severely impacted area, as stated in the report. The number of villages estimated to be affected was slightly less than the reported 138. The estimated flooded arable land area differs considerably from the reported amount for inundated arable land. The estimated area was 1.6 times that of the reported number. Time differences between remote sensing and reporting, 
errors of information processing and analysis, and insufficient exposure information updating shaped the estimated deviation.

More than 20 emergency mapping products and estimation reports of the 2015 Myanmar flood have been produced from a reference map based on pre-flood data to estimate the information on flooded areas drawn from multiple sources. These products have been available to the Myanmar government for emergency management support and have been recognized for their efficient service.

\section{Discussion}

This case study shows that integrating global open and other sourced geo-information could serve as a practical approach to major disaster assessment, especially for those countries that lack national spatial data infrastructure. However, even as more sources of information become available, there are still major discrepancies between the information provided and requirements in terms of accuracy, timeliness, and readability. To address these gaps, communities must manage issues related to geo-information and damage assessment. First, datasets required for damage assessments are typically large and drawn from several different agencies, rendering it difficult to access these data within a short period of time. Second, although open data policies are promoted through several initiatives, most geo-information of less than a 10-meter resolution for affected element estimations is strictly limited for sharing or open use. High resolution remote sensing imagery is also very limited in terms of emergency use. Third, as geo-information typically takes several forms due to a lack of uniform standards and professional processing capacities in most developing countries, it typically takes a long time to prepare data and to conduct analyses, as datasets are not typically well organized. In addition, every methodology has advantages and limitations, and determining ways to use them in an integrated manner to support outcome synergy is a major challenge. Further, while new advances in the field of geo-information, such as crowdsourcing, are changing the ways in which information is collected and integrated from multiple sources and offered to the end user [50-55], the validation and analysis of such information must be explored for better use.

\section{Conclusions}

Due to the complexities and factors involved in disaster damage assessments, geospatial information drawn from multiple sources through an integrated approach at global and local levels should be used to support disaster relief, response, and recovery operations. To address challenges faced by disaster management agencies and to improve the use of existing information for disaster damage estimations, the following issues should be taken into account: (1) Produce more global datasets through inclusive and collaborative platforms to facilitate data access and update them periodically. At the same time, make full use of existing geo-information resources so that they add value through integrated information service platforms; (2) Develop methodologies specific to each disaster and validate them in conjunction with available data sources, damage assessment indicators, and guidelines for their transfer software tools for ease of use; (3) Shift the practice of generating 'information based on data' to developing 'knowledge based on information' through in-depth requirement analyses and solutions-oriented methodologies to generate the products needed for decision-making; (4) Develop standards related to datasets, methodologies, products, and platforms for the superior integration and utilization of geo-information to enhance disaster preparedness for an effective response, as spelled out under the Sendai Framework for Disaster Risk Reduction: 2015-2030; (5) Construct a geo-information integrated platform for information resource searching, use, and development at the global scale with data catalogs, metadata, and clearly specified policies; (6) Explore the potential and modalities of new advances and innovations such as big data, cloud computing, and environment modeling for superior disaster reduction applications [56-58].

Acknowledgments: This work was supported by the National Natural Science Foundation of China under Grant (41301591). 
Author Contributions: Yan Cui collected and processed the data; Haixia He extracted information; Ming Liu performed the data analysis; Shirish Ravan contributed to the discussion and made revisions; Suju Li wrote the paper.

Conflicts of Interest: The authors declare no conflicts of interest.

\section{References}

1. Subra, S. Global Challenges Need Global Solutions. Nature 2012, 490, 337-338.

2. Guha-Sapir, D.; Hoyois, P.; Below, R. Annual Disaster Statistical Review 2015: The Numbers and Trends; CRED: Brussels, Belgium, 2016.

3. Hiroyuki, M.; Masahiko, N.; Ryosuke, S. Reviews of Geospatial Information Technology and Collaborative Data Delivery for Disaster Risk Management. ISPRS Int. J. Geo-Inf. 2015, 4, 1936-1964.

4. Wald, D.J.; Jaiswal, K.; Marano, K.D.; Bausch, D.; Hearne, M. PAGER-Rapid Assessment of an Earthquake's Impact: U.S. Geological Survey Fact Sheet 2010-3036. Available online: https:/ / pubs.usgs.gov/fs/2010/ 3036/pdf/FS10-3036.pdf (accessed on 3 May 2017).

5. Andrea, A.; Piero, B.; Franca, D.; Fabio, G.T. Rapid Mapping: Geomatics role and research opportunities. Rendiconti Lincei 2015, 26, 63-73. [CrossRef]

6. Global Disaster Alert and Coordination System. Available online: http://www.gdacs.org (accessed on 3 May 2017).

7. Fan, Y.; Yang, S.; Wang, W.; Wang, L.; Nie, J.; Zhang, B. Study on Urgent Monitoring and Assessment in Wenchuan Earthquake. J. Remote Sens. 2008, 12, 858-864.

8. Martin, H.; Linda, S.; Nandin, E.T.; Steffen, F. Towards an Integrated Global Land Cover Monitoring and Mapping System. Remote Sens. 2016, 8, 1036. [CrossRef]

9. Chen, J.; Li, S.N.; Wu, H.; Chen, X.J. Towards a collaborative global land cover information service. Int. J. Digital Earth 2017, 10, 356-370. [CrossRef]

10. Chen, J.; Chen, J.; Liao, A.; Cao, X.; Chen, L.; Chen, X.; He, C.; Han, G.; Peng, S.; Lu, M. Global land cover mapping at 30m resolution: A pok-based operational approach. ISPRS J. Photogramm. Remote Sens. 2015, 103, 7-27. [CrossRef]

11. Gong, P.; Wang, J.; Yu, L.; Zhao, Y.; Zhao, Y.; Liang, L.; Niu, Z.; Huang, X.; Fu, H.; Liu, S.; et al. Finer resolution observation and monitoring of global land cover: First mapping results with Landsat TM and ETM+ data. Int. J. Remote Sens. 2013, 34, 2607-2654. [CrossRef]

12. Hannes, T.; Joachim, F.; Stefan, D. Regions Set in Stone-Delimiting and Categorizing Regions in Europe by Settlement Patterns Derived from EO-Data. ISPRS Int. J. Geo-Inf. 2017, 6, 55. [CrossRef]

13. Open Government Partnership. Available online: https://www.opengovpartnership.org (accessed on 3 May 2017).

14. Open Data Charter. Available online: http:/ / opendatacharter.net/ (accessed on 3 May 2017).

15. International Charter Space \& Major Diasater. Available online: http://www.disasterscharter.org (accessed on 3 May 2017).

16. Group on Earth Observations. Available online: http://www.earthobservations.org (accessed on 3 May 2017).

17. The Sendai Framework for Disaster Risk Reduction: 2015-2030. Available online: http://www.unisdr.org/ files/43291_sendaiframeworkfordrren.pdf (accessed on 3 May 2017).

18. Earthquake Hazards Program of USGS. Available online: http:/ / earthquake.usgs.gov/data/shakemap/ (accessed on 3 May 2017).

19. Wu, H.; Adler, R.F.; Tian, Y.; Huffman, G.J.; Li, H.; Wang, J. Real-time global flood estimation using satellite-based precipitation and a coupled land surface and routing model. Water Resour. Res. 2014, 50, 2693-2717. [CrossRef]

20. Global Flood Monitoring System (GFMS). Available online: http://flood.umd.edu/ (accessed on 3 May 2017).

21. NOAA Satellites and infomation. Available online: http://rammb.cira.colostate.edu/products/tc_realtime/ index.asp (accessed on 3 May 2017).

22. Natural Hazards Data, Image and Education. Available online: https://ngdc.noaa.gov/hazard/hazards. shtml (accessed on 3 May 2017). 
23. Understanding Risk in an Evolving World: Emerging Best Practices in Natural Disaster Risk Assessment. Available online: https://www.gfdrr.org/sites/gfdrr/files/publication/Understanding_Risk-Web_Versionrev_1.8.0.pdf (accessed on 3 May 2017).

24. Center for International Earth Science Information Network-CIESIN—Columbia University. Documentation for the Gridded Population of the World, Version 4 (GPWv4); NASA Socioeconomic Data and Applications Center: Palisades, NY, USA, 2016.

25. Andreas, F.; Thomas, E.; Wieke, H.; Mattia, M.; Julian, Z.; Achim, R.; Martin, K.; Michael, W.; Hannes, T. The global urban footprint-Processing status and cross comparison to existing human settlement products. In Proceedings of the 2014 IEEE Geoscience and Remote Sensing Symposium, Quebec City, QC, Canada, 13-18 July 2014; pp. 4816-4819.

26. Chen, J.; Ban, Y.F.; Li, S.N. China: Open Access to Earth Land-cover Map. Nature 2014, 514, 434.

27. The International Disaster Database. Available online: http://www.emdat.be/ (accessed on 3 May 2017).

28. Reliefweb. Available online: http:/ / reliefweb.int/ (accessed on 3 May 2017).

29. IWG-SEM (2014) Emergency Mapping Guidelines. Available online: http://www.unspider.org/sites/ default/files/IWG_SEM_EmergencyMappingGuidelines_A4_v1_March2014.pdf (accessed on 3 May 2017).

30. Stefan, V.; Fabio, G.T.; Josh, L.; Jan, K.; Brenda, J.; Tobias, S.; Gabriel, P.; Kazuya, K.; Manzul, K.H.; Lorant, C.; et al. Global trends in satellite-based emergency mapping. Science 2016, 353, 247-252. [CrossRef]

31. Wang, M.; Li, Q.; Hu, Q.; Zhou, M. Quality analysis of open street map data. In International Archives of the Photogrammetry, Remote Sensing and Spatial Information Sciences, Proceedings of the 8th International Symposium on Spatial Data Quality, Hong Kong, China, 30 May-1 June 2013; ISPRS: Hanover, Germany, 2013; pp. 155-158.

32. Pascal, N.; Peter, S.; Alexander, Z. Collaborative mapping and Emergency Routing for Disaster Logistics-Case studies from the Haiti earthquake and the UN portal for Afrika. Available online: http:/ / wiki.openstreetmap.org/wiki/Research (accessed on 3 May 2017).

33. Imi, Y.; Hayakawa, T.; Ito, T. Analyzing the effect of open street map during crises: The great east Japan earthquake. In Proceedings of the 14th International Conference on Commerce and Enterprise Computing, Hangzhou, China, 9-11 September 2012; pp. 126-130.

34. Abu, B.S.; Fusanori, M. Integration of Spatial Analysis for Tsunami Inundation and Impact Assessment. J. Geog. Inf. Syst. 2014, 6, 11-22.

35. Teimour, M.; Delavar, M.R.; Koyaie, S.; Chavoshi, S.H.; Moghaddm, H.K. A SDSS-Based Earthquake Damage Assessment for Emergency Response: Case Study in BAM. Available online: http:/ /www.isprs. org/proceedings/XXXVII/congress/8_pdf/2_WG-VIII-2/55.pdf (accessed on 3 May 2017).

36. Azar, D.; Engstrom, R.; Graesser, J.; Comenetz, J. Generation of fine scale population layers using multi-resolution satellite imagery and geospatial data. Remote Sens. Environ. 2013, 219-232. [CrossRef]

37. Debarati, G.S.; Philippe, H. Estimating populations affected by disasters: A review of methodological issues and research gaps. Global Sustainable Report 2015. Available online: http://cred.be/pubulication (accessed on 3 May 2017).

38. Carina, V.; Karel, J.; Dieter, D.P.; Dmitrii, K.;Ŝtěpán, K.; Pieter, C.; Otakar, Č. Geodata interoperability and harmonization in transport: A case study of open transport net. Open Geospat. Data Softw. Stand. 2017, 2, 3. [CrossRef]

39. Jerome, E.D.; Edward, A.B.; Phillip, R.C.; Richard, C.D.; Brian, A.W. LandScan: A Global Population Database for Estimating Populations at Risk. Photogramm. Eng. Remote Sens. 2000, 66, 849-857.

40. Corbane, C.; Lemoine, G.; Kauffmann, M. Relationship between the spatial distribution of SMS messages reporting needs and building damage in 2010 Haiti disaster. Nat. Hazards Earth Syst. Sci. 2012, 12, 255-265. [CrossRef]

41. Lu, L.; Guo, H.; Corbane, C. Building Damage Assessment with VHR Images and Comparative Analysis for Yushu Earthquake, China. Disaster Adv. 2013, 6, 37-44.

42. 2010 Haiti Earthquake Final Report. A world Bank/GFDRR IMAGECAT REPORT: Post-disaster Building Damage Assessment Using Satellite and Aerial Imagery Interpretation, Field Verification and Modeling. Available online: https://www.gfdrr.org/sites/gfdrr.org/files/publication/2010haitiearthquakepostdisasterbuildingdamageassessment.pdf (accessed on 3 May 2017).

43. Disaster Information Management System. Available online: http://www.desinventar.net/gft.html (accessed on 8 June 2017). 
44. Perera, I.; Meedeniya, D.; Benerjee, I.; Choudhury, J. Educating Users for Disaster Management: An Exploratory Study on Using Immersive Training for Disaster Management. In Proceedings of the 2013 IEEE International Conference in MOOC, Jaipur, India, 20-22 December 2013; pp. 245-250.

45. Wikipedia. Available online: https:/ / en.wikipedia.org/wiki/Myanmar (accessed on 3 May 2017).

46. 2016 Myanmar Humanitarian Response Plan. Available online: http://reliefweb.int/sites/reliefweb.int/ files/resources/2016_myanmar_hrp_final.pdf (accessed on 3 May 2017).

47. United Nations Office for the Coordination of Humanitarian Affairs (OCHA). Myanmar: Floods emergency situation report No. 5 (as of 21 August 2015). Available online: http://reliefweb.int/report/myanmar/ (accessed on 3 May 2017).

48. Myanmar Information Management Unit. Available online: http://www.themimu.info/baseline-datasets (accessed on 3 May 2017).

49. Zhang, T.; Yang, X.M.; Hu, S.S.; Su, F.Z. Extraction of Coastline in Aquaculture Coast from Multispectral Remote Sensing Images: Object-Based Region Growing Integrating Edge Detection. Remote Sens. 2013, 5, 4470-4487. [CrossRef]

50. Max, C.; Lea, S. Data democracy-Increased supply of geospatial information and expanded participatory processes in the production of data. Int. J. Digital Earth 2015, 8, 679-693. [CrossRef]

51. Michael, F.G.; Glennon, J.A. Crowdsourcing geographic information for disaster response: A research frontier. Int. J. Digital Earth 2010, 3, 231-241. [CrossRef]

52. Stephane, R.; Eliane, P.Z.; Boris, M. GeoWeb and crisis management: Issues and perspectives of volunteered geographic information. GeoJournal 2013, 78, 21-40. [CrossRef]

53. Kazuya, K.; Noriko, A.; Futoshi, T. Space-based response to the 2011 Great East Japan Earthquake: Lessons learnt from JAXA's support using earth observation satellites. Int. J. Disaster Risk Reduct. 2015, 12, 134-153.

54. Stefan, V.; Tobias, S.; André, T.; Monika, G.; Enrico, S.; Harald, M. Rapid Damage Assessment and Situation Mapping: Learning from the 2010 Haiti Earthquake. Photogramm. Eng. Remote Sens. 2011, 77, 923-931.

55. Luke, B.; Shubharoop, G.; Marjorie, G.; Shary, H.; Jay, B.; Stuart, G.; Albert, Y.L.; Charles, H. Crowdsourcing earthquake damage assessment using remote sensing imagery. Ann. Geophys. 2011, 54. [CrossRef]

56. Yang, C.W.; Yu, M.Z.; Hu, F.; Jiang, Y.Y.; Li, Y. Utilizaing Cloud Computing to address big geospatial data challenges. Comput. Environ. Urban Syst. 2017, 61, 120-128. [CrossRef]

57. Yang, C.W.; Huang, Q.Y.; Li, Z.L.; Liu, K.; Hu, F. Big Data cloud computing: Innovation opportunities and challenges. Int. J. Digital Earth 2017, 10, 13-53. [CrossRef]

58. Papadimitriou, F. Modelling Landscape Complexity for Land Use Management in Rio de Janeiro, Brazil. Land Use Policy 2012, 29, 855-861. [CrossRef] 